of the most important factors influencing pest risk, and improve our ability to provide realistic scenarios for the future. Scenarios of future pest and disease distributions under climate change support prioritization in agricultural research programmes. For example, if it is likely that a particular disease will become more important in a region, crop-breeding programmes can respond by incorporating better resistance to that disease in locally adapted varieties.

The prevalence of crop pests is a function of many factors, so identifying particular drivers of change is challenging ${ }^{9}$ (Fig. 1). If we wish to ask whether crop pests have altered distributions because of climate change, this is complicated by the many other factors that have changed simultaneously, even when long-term data are available ${ }^{10}$. It is reasonable to expect that higher temperatures will often reduce limitations on pest overwintering and increase the number of pest generations per year (Fig. 1A). However, other factors simultaneously influence pest risk at any location, including host genotypic and phenotypic resistance, where phenotypic resistance may respond to weather variables such as temperature (Fig. 1B). When multiple observers and multiple levels of sampling effort are involved, this adds another layer of uncertainty when comparing the actual distribution of pests and reported distributions (Fig. 1C).

Bebber and colleagues ${ }^{4}$ provide a stimulating analysis of changes in pest distributions, along with a new set of hypotheses to engage scientists working with pests. Future 'big data' analyses may address the geographic distribution of pest genomes and microbial metagenomes associated with plants and soil, including analysis of the geographic spread of genes important in crop damage. Cell phone availability may facilitate analysis of global digital images of crop damage. Better data archiving systems and more data sharing are needed to support future synthetic analyses. For addressing large-extent questions, we also need advances in methods to evaluate more directly the factors that lead, not only to pest risk, but also to reporting of observations, to support understanding of what variables may be good proxies for sampling effort.

Karen A. Garrett is in the Department of Plant Pathology, Kansas State University, Manhattan, Kansas 66506, USA.

e-mail:kgarrett@ksu.edu

References

1. Coakley, S. M., Scherm, H. \& Chakraborty, S. Ann. Rev. Phytopathol. 37, 399-426 (1999)

2. Jeger, M. J. \& Pautasso, M. New Phytol. 177, 8-11 (2008).

3. Shaw, M. W. \& Osborne, T. M. Plant Pathol. 60, 31-43 (2011)

4. Bebber, D. P., Ramotowski, M. A. T. \& Gurr, S. J. Nature Clim. Change 3, 985-988 (2013).

5. Mayer-Schönberger, V. \& Cukier, K. Big Data: A Revolution That Will Transform How We Live, Work, and Think (Houghton Mifflin Harcourt, 2013).

6. Sutherst, R. W. J. Biogeogr. 30, 805-816 (2003).

7. Venette, R. C. et al. BioScience 60, 349-362 (2010).

8. Pasiecznik, N. M. et al. EPPO Bull. 35, 1-7 (2005).

9. Garrett, K. A. et al. Plant Pathol. 60, 15-30 (2011).

10. Hannukkala, A. O., Kaukoranta, T., Lehtinen, A. \& Rahkonen, A. Plant Pathol. 56, 167-176 (2007).

\title{
Bottom up in the tropics
}

A study reveals that recent warming in the Indian Ocean and in the Pacific 'warm pool' has caused a cooling near the top of the tropical troposphere above, leading to less water vapour entering the stratosphere.

\section{Qiang Fu}

W

ater vapour in the stratosphere is a greenhouse gas. It is constrained from entering the stratosphere in the tropics by the thermal boundary between the stratosphere and troposphere $^{1}$ - the tropical tropopause, the coldest point in the lower atmosphere. Cold-point temperatures at the tropical tropopause (Fig. 1a) have important implications for both stratospheric chemistry $^{2}$ and global climate change ${ }^{3}$. The importance of the spatial distribution of temperature (Fig. 1b) is well recognized, as the temperature minimum is relevant to cloud formation and subsequent dehydration through atmospheric circulation $^{4}$. In the boreal winter, for example, the lowest cold-point temperatures over the warm pool in the tropical western Pacific govern the amount of water vapour that enters the stratosphere ${ }^{5}$. It is thus critically important to understand how the zonal (longitudinal) structure of the tropical cold-point temperature would respond to global warming. Now, reporting in the
Journal of Geophysical Research, Garfinkel and co-workers ${ }^{6}$ find that the warming in the tropical upper troposphere over the past 30 years has been strongest over the Indo-Pacific warm pool, where cooling near the tropopause has been strongest. They suggest that warming in the Indian Ocean and the Pacific warm pool has led to zonal asymmetry in atmospheric temperature trends, and that such trends may continue in the future.

Temperatures near the tropical tropopause are determined by a complex combination of stratospheric (top-down) and tropospheric (bottom-up) processes ${ }^{7}$. The zonal structures at $100 \mathrm{hPa}$ (Fig.1b) closely resemble the mean pattern of the equatorial planetary waves - large-scale perturbations of the atmospheric dynamical structure. These are driven by massive convection over the Indo-Pacific warm $\mathrm{pool}^{8}$, with the lowest temperatures and largest cirrus cloud fractions over the western Pacific and Maritime Continent (which includes the islands of Indonesia,
New Guinea and Malaysia, and the surrounding shallow seas) ${ }^{9}$. The signature of the equatorial planetary waves is also evident in the temperature variability over intraseasonal to interannual timescales ${ }^{9}$. The responses of temperature structures at 100 and $250 \mathrm{hPa}$ are reversed in sign because the maximum amplitude of equatorial planetary waves with opposite phases occurs at these two levels. The temperatures and cloud fraction near the tropical tropopause are also strongly modulated by extra-tropical stratospheric waves. These drive the Brewer-Dobson circulation (BDC) - a large-scale latitudinal circulation in the stratosphere with air rising across the tropical tropopause, moving polewards and sinking towards the extra-tropical troposphere - which is particularly evident in their seasonal cycles $^{9-11}$ (Fig.1c). In contrast to the equatorial planetary waves, the extra-tropical stratospheric waves are associated with zonally symmetric temperature anomalies in the lower stratosphere. 

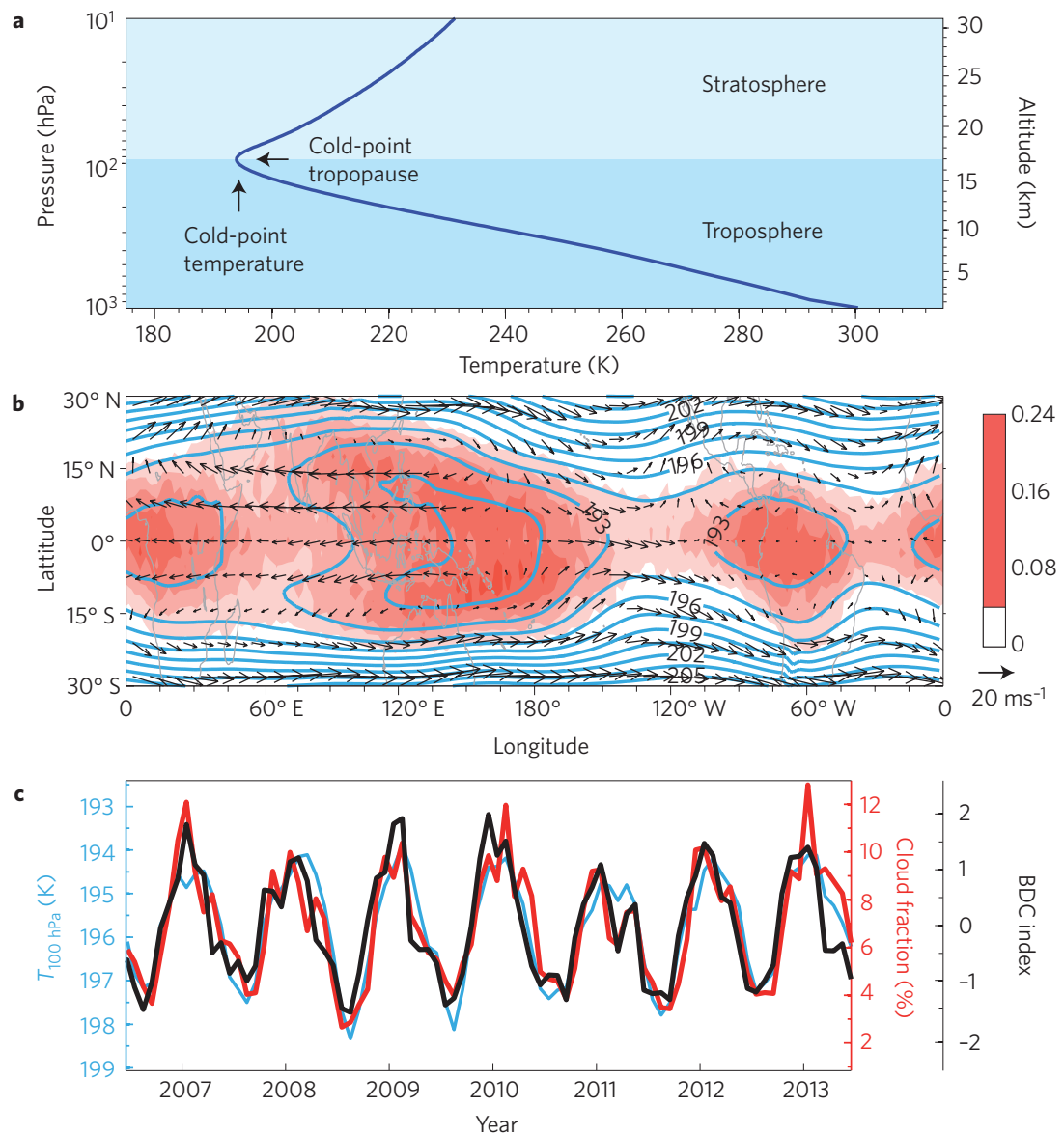

Figure 1 | Temperature near the tropopause in the tropics. $\mathbf{a}$, Vertical profile of temperature. $\mathbf{b}$, Horizontal distributions of temperature (contours) and winds (vectors) at $100 \mathrm{hPa}$ from reanalysis data. Cloud fractions for clouds with bases higher than $15 \mathrm{~km}$ are also shown (colour scale). c, Temporal variations in temperature at $100 \mathrm{hPa}$, cloud fractions for clouds with bases higher than $15 \mathrm{~km}$ (averaged over the tropics) and the BDC index 11 are shown. The tick mark for each year indicates 1 January. Data from ref. 14.

Temperatures in the lower stratosphere and upper troposphere have been changing during the past few decades. Although many studies have focused on the zonal mean component of temperature trends ${ }^{12}$, Garfinkel and co-workers concentrate on the zonally asymmetric component, and in particular on trends near the coldest point in the tropopause region. Satellite observations are used to document the zonal structure of the temperature trends, which is strongest in January, February and March. The lower stratosphere over the warm-pool region is found to have cooled more than the zonal mean, whereas the central and eastern Pacific have cooled less. However, the structure of the upper tropospheric trends is opposite in phase, with the largest warming over the warm pool. All atmospheric chemistryclimate models that are driven by observed sea surface temperature (SST) and external forcings are shown to accurately capture the observed zonal variations of these trends.
To understand the cause of the zonal structure of atmospheric temperature trends in January-March, Garfinkel et al. use an atmospheric chemistry-climate model with observed SST as the only forcing that varies over time. The simulated structure of temperature trends is similar to those from more comprehensive model integrations and satellite observations, indicating that the SST changes have driven the zonal asymmetry. An increase in SST over the Indian Ocean and the far western Pacific enhances the deep convection and thus the latent heat release in the upper troposphere that increases the amplitude of the equatorial planetary waves. This leads to warming near $250 \mathrm{hPa}$, but cooling near $100 \mathrm{hPa}$, over the Indo-Pacific warm pool. Their study represents the first effort to document and understand the cause of zonal structures in tropical atmospheric temperature trends since 1980.
Changes in the cold-point temperature would be expected to alter the amount of water vapour entering the stratosphere. The model simulation shows that less water vapour enters the stratosphere as a result of the cooling near the cold-point tropopause over the Indo-Pacific warm pool, driven by the increased SST there ${ }^{6}$. However, their work does not explain the changes in lower-stratospheric water vapour content that have been observed in the past few decades. This could partly be because other factors - such as the change of the $\mathrm{BDC}^{13}$ - would also affect the cold pointtemperatures (Fig.1c). In addition, the impact of the equatorial planetary waves and upward motion associated with the $\mathrm{BDC}$ on tropical thin cirrus clouds need to be investigated, and could have a warming feedback to the climate system ${ }^{14}$.

Past increases in the Indian Ocean SST have been directly linked to the global warming ${ }^{15}$ and may continue in the future. Garfinkel et al. show that there is a cooling near the tropical tropopause over the Indo-Pacific warm-pool region and thus less water vapour entering the stratosphere. This response to the SST change is due to the enhanced equatorial planetary waves. A decrease in stratospheric water vapour may lead to a slight cooling of global surface temperatures. This study demonstrates that it is of paramount importance to pay attention to, and understand the cause of, the patterns of SST changes that are related to global warming.

Qiang Fu is in the Department of Atmospheric Sciences, University of Washington, Seattle, Washington 98195, USA.

e-mail:qfu@atmos.washington.edu

\section{References}

1. Brewer, A. W. Q. J. R. Meteorol. Soc. 75, 351-363 (1949).

2. Braasseur, G. P. \& Solomon, S. Aeronomy of the Middle Atmosphere 3rd edn (Springer, 2005).

3. Solomon, S. et al. Science 327, 1219-1222 (2010)

4. Holton, J. R. \& Gettelman, A. Geophys. Res. Lett. 28, 2799-2802 (2001).

5. Fueglistaler, S., Bonazzola, M., Haynes, P. H. \& Peter, T. J. Geophys. Res. 110, D08107 (2005).

6. Garfinkel, C. I., Waugh, D. W., Oman, L. D., Wang, L. \& Hurwitz, M. M. J. Geophys. Res. http://dx.doi.org/10.1002/ jgrd.50772 (2013).

7. Girse, K. M. \& Thompson, D. W. J. J. Atmos. Sci. 70, 1084-1102 (2013)

8. Highwood, E. J. \& Hoskins, B. J. Q. J. R. Meteorol. Soc. 124, 1579-1604 (1998).

9. Virts, K. S. \& Wallace, J. M. J. Atmos. Sci. 67, 3097-3112 (2010).

10. Yulaeva, E., Holton, J. R. \& Wallace, J. M. J. Atmos. Sci. 51, 169-174 (1994)

11. Ueyama, R. \& Wallace, J. M. J. Atmos. Sci. 67, 1232-1246 (2010).

12. Wang, L. \& Waugh, D. W. J. Geophys. Res. 117, D00109 (2012).

13. Butchart, N. et al. Clim. Dynam. 27, 727-741 (2006)

14. Winker, D. M. et al. Bull. Am. Meteorol. Soc. 91, 1211-1229 (2010).

15. Knutson, T. R. et al. J. Clim. 19, 1624-1651 (2006).

Q.F. is supported by NASA grant NNX13AN49G. 